\title{
Fractional Flow on TOF-MRA as a Measure of Stroke Risk in Children with Intracranial Arterial Stenosis
}

This information is current as of April 25, 2023.
A.Y. Ibrahim, A. Amirabadi, M.M. Shroff, N. Dlamini, P. Dirks and P. Muthusami

AJNR Am J Neuroradiol 2020, 41 (3) 535-541

doi: https://doi.org/10.3174/ajnr.A6441

http://www.ajnr.org/content/41/3/535 


\title{
Fractional Flow on TOF-MRA as a Measure of Stroke Risk in Children with Intracranial Arterial Stenosis
}

\author{
(D) A.Y. Ibrahim, (D) A. Amirabadi, (D) M.M. Shroff, (D) N. Dlamini, (DP. Dirks, and (DP. Muthusami
}

\begin{abstract}
BACKGROUND AND PURPOSE: Conventional angiography is the criterion standard for measuring intracranial arterial stenosis. We evaluated signal intensity ratios from TOF-MRA as a measure of intracranial stenosis and infarct risk in pediatric stroke.
\end{abstract}

MATERIALS AND METHODS: A retrospective study was undertaken in children with intracranial arterial stenosis, who had TOF-MRA and conventional angiography performed within 6 months. Arterial diameters were measured for percentage stenosis. ROI analysis on TOF-MRA measured signal intensity in pre- and poststenotic segments, with post-/pre-signal intensity ratios calculated. The Pearson correlation was used to compare percentage stenosis on MRA with conventional angiography and signal intensity ratios with percentage stenosis; the point-biserial correlation was used for infarcts compared with percentage stenosis and signal intensity ratios. Sensitivity, specificity, and positive and negative predictive values were calculated for determining severe ( $\geq 70 \%)$ stenosis from MRA and signal intensity ratios against the criterion standard conventional angiography. $P<.05$ was considered statistically significant.

RESULTS: Seventy stenotic segments were found in 48 studies in 41 children (median age, 11.0 years; range, 5 months to 17.0 years; male/female ratio, 22:19): 20/41 (48.8\%) bilateral, $11 / 41$ (26.8\%) right, and 10/41 (24.4\%) left, with the most common site being the proximal middle cerebral artery (22/70, 31\%). Moyamoya disease accounted for $27 / 41(65.9 \%)$. Signal intensity ratios and conventional angiography stenosis showed a moderate negative correlation $(R=-0.54, P<.001)$. Receiver operating characteristic statistics showed an area under the curve of 0.86 for using post-/pre-signal intensity ratios to determine severe ( $\geq 70 \%)$ carotid stenosis, yielding a threshold of 1.00 . Sensitivity, specificity, and positive and negative predictive values for severe stenosis were the following-MRA: $42.8 \%, 58.8 \%, 30.0 \%$, and $71.4 \%$; signal intensity ratio $>1.00: 97.1 \%, 77.8 \%$, $71.7 \%$, and $97.4 \%$; combination: $75.5 \%$, $100 \%, 100 \%$, and $76.8 \%$, respectively. Signal intensity ratios decreased with increasing grade of stenosis (none/mild-moderate/ severe/complete, $P<.001)$ and were less when associated with infarcts $(0.81 \pm 0.52$ for arteries associated with downstream infarcts versus $1.31 \pm 0.55$ for arteries without associated infarcts, $P<.001$ ).

CONCLUSIONS: Signal intensity ratios from TOF-MRA can serve as a noninvasive measure of intracranial arterial stenosis and allow identification of high-risk lesions in pediatric stroke.

ABBREVIATIONS: $\mathrm{CA}=$ conventional angiography; $\mathrm{SI}=$ signal intensity

$\mathrm{S}$ troke in children is 1 of the top 10 causes of death in childhood. ${ }^{1,2}$ The incidence of all strokes in children is reported to be $2-13$ per 100,000 person-years in developed countries. ${ }^{3-6}$

Received August 16, 2019; accepted after revision January 4, 2020.

From the Department of Diagnostic Imaging (A.Y.I., A.A., M.M.S., P.M.), Division of Neurology (N.D.) and Division of Neurosurgery (P.D.), Department of Surgery, The Hospital for Sick Children, University of Toronto, Toronto, Ontario, Canada; and Department of Clinical Sciences (A.Y.I.), Faculty of Medicine, Yarmouk University, Irbid, Jordan.

The study was approved by the Institutional Research Ethics Board with REB 1000062860. Written informed consent was obtained from all patients/parents prior to the procedures.

Please address correspondence to Ala' Y. Ibrahim, MD, Department of Clinical Sciences, Faculty of Medicine, Yarmouk University, P.O. Box 566, 21163 Irbid, Jordan; e-mail: dr.alaa_yonis@yahoo.com; @Ala_Y_Ibrahim

http://dx.doi.org/10.3174/ajnr.A6441
Childhood arteriopathies are the most common identifiable cause of arterial ischemic stroke, accounting for up to two-thirds of cases in a previously healthy child. ${ }^{7-11}$ The most common causes of intracranial arterial steno-occlusive disease in children are Moyamoya disease, focal dissection, transient cerebral arteriopathy, and post-varicella arteriopathy, ${ }^{12-14}$ though a number of other syndromic and nonsyndromic associations exist. ${ }^{15}$

Stroke in children is commonly assessed and followed by MR imaging, which is noninvasive and free of ionizing radiation. ${ }^{12}$ Vascular assessment is commonly performed using TOF-MRA, which gives a global assessment of vascular disease. However, TOF-MRA is amenable to several artifacts resulting from the inherent technique and is known to overestimate stenotic lesions while underevaluating arteries that are severely affected. ${ }^{16-18}$ 


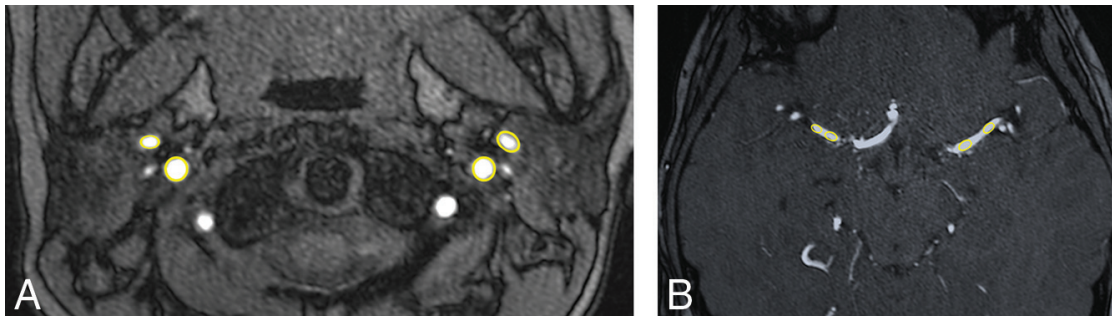

FIG 1. Measurement of arterial signal intensity from TOF-MRA using ROI analysis. A, Prestenotic ROI. B, Poststenotic ROI.

Often, for further clarification of equivocal findings, contrastenhanced MR imaging or CT angiography is performed, though these too have certain drawbacks. Conventional angiography (CA) remains the criterion standard test to diagnose intracranial arterial stenosis and accurately quantify severity. ${ }^{19-21}$ This is, however, an invasive test, using ionizing radiation and requires general anesthesia in most children and a dedicated pediatric neuroangiographic service to maximize safety.

The signal intensity (SI) within arteries on TOF-MRA is dependent on the number of moving spins and the velocity of blood flow and thus has the potential to noninvasively assess the downstream effect of arterial stenosis. Ratios derived from SI on TOFMRA have been shown to correlate with cerebral perfusion as measured by CT perfusion and SPECT in adults with intracranial carotid stenosis. $^{22,23}$ It is not known whether arterial SI ratios measured from TOF-MRA can accurately estimate the degree of intracranial carotid stenosis as measured on conventional angiography in children presenting with stroke and whether these ratios can help identify high-risk lesions. We hypothesized the following: 1) SI ratios calculated from TOF-MRA are significantly correlated with percentage stenosis measured from conventional angiography, 2) SI ratios calculated from TOF-MRA are significantly correlated with infarct burden, and 3) SI ratios serve as stronger predictors of severe $(>70 \%)$ intracranial arterial stenosis than stenosis measured from TOF-MRA.

\section{MATERIALS AND METHODS \\ Subjects and Imaging}

An institutional review board-approved retrospective study was undertaken on children 18 years of age or younger with an imaging diagnosis of intracranial carotid artery stenosis at our tertiary pediatric institution (The Hospital for Sick Children) between January 1, 2000, and November 10, 2018. The need for individual consent for this retrospective review was waived by the Institutional Research Ethics Board. A keyword search was performed on the radiology departmental data base to identify all studies reported with intracranial arterial stenosis. Studies were included that had both TOF-MRA and conventional angiography performed within 6 months of each other. Patients with tandem lesions (ie, 2 noncontiguous stenotic lesions), those with MRA and conventional angiography performed more than 6 months apart, and patients with suboptimal imaging quality resulting in unreliable SI or stenosis measurement were excluded.
MR imaging was performed on a $1.5 \mathrm{~T}$ magnet (Achieva; Philips Healthcare, Best, the Netherlands) or a 3T magnet (Magnetom Skyra; Siemens, Erlangen, Germany, or Achieva) with a 32-channel transmit-receive head coil. The examination included standard T1-, T2-, and FLAIR-weighted sequences, followed by TOF-MRA with the following parameters-1.5T MRA: TR/TE = $25 / 6.91 \mathrm{~ms}$, flip angle $=20^{\circ}$, bandwidth $=109 \mathrm{~Hz}, \mathrm{FOV}=18 \mathrm{~cm}$, spatial resolution $=0.70 \times 0.90 \times 1.0 \mathrm{~mm}$ (interpolated to $0.5 \times 0.5 \times 0.5 \mathrm{~mm}$ ), $1-\mathrm{mm}$ section thickness with 0.5 -mm overlap; 3T MRA: TR/TE $=25 / 3.81 \mathrm{~ms}$, flip angle $=$ $18^{\circ}$, bandwidth $=186 \mathrm{~Hz}, \mathrm{FOV}=18 \mathrm{~cm}$, spatial resolution $=$ $0.40 \times 0.70 \times 1.0 \mathrm{~mm}$ (interpolated to $0.5 \times 0.5 \times 0.5 \mathrm{~mm}$ ), $1.0-\mathrm{mm}$ section thickness with 0.5 -mm overlap. Con-ventional angiography was performed by 1 of 2 interventional neuroradiologists (P.M. or M.M.S.) in a biplane neuroangiography suite (Artis Q; Siemens). All procedures were performed with the patient under general anesthesia through femoral artery access and systemic heparinization using a $4 \mathrm{~F}$ diagnostic catheter with standard projections and an iodinated contrast agent (iohexol, Omnipaque $300 \mathrm{mg}$ I/mL; GE Healthcare, Piscataway, New Jersey) injected through a power injector at $3-5 \mathrm{~mL} / \mathrm{s}$, depending on the age and arterial size.

\section{Data Analysis and Image Processing}

Images and reports were analyzed by a fellowship-trained pediatric neuroradiologist (A.Y.I.), with discrepancies resolved by the senior author (P.M.). Electronic chart review and image analysis on the PACS system were performed for included patients to collect the following data: demographics (age at diagnosis, sex), time interval between MRA and conventional angiography, laterality of stenosis (right/left/bilateral), specific location/segment of artery involved (petrous ICA, cavernous ICA, paraclinoid ICA, pre-communicating ICA, terminal ICA, postbifurcation), any ischemic events regardless of the association with the territory of the stenotic lesion, and any ischemic or hemorrhagic events not associated with the stenotic lesion. Stenosis was regarded as symptomatic if ischemic lesions on MR imaging were territorially consistent with the stenotic lesion. Downstream infarcts were defined as any abnormal bright T2/FLAIR lesions in the vascular distribution of the stenotic segment without mass effect.

Arterial diameters were measured to assess the percentage of ICA stenosis on MRA and CA. The percentage stenosis on MRA and catheter cerebral angiography was measured as described previously. ${ }^{24}$ In summary, percentage stenosis of an intracranial artery is $\left[\left(1-\left(D_{\text {stenosis }} / D_{\text {normal }}\right)\right] \times 100\right.$, where $D_{\text {stenosis }}$ is the diameter of the ICA at the maximally stenotic segment and $\mathrm{D}_{\text {normal }}$ is the diameter of the most adjacent proximal normal artery (usually the petrous ICA). If the proximal segment was diseased, contingency sites were chosen to measure $\mathrm{D}_{\text {normal }}$ : the most adjacent nondiseased distal artery (second choice, usually the terminal ICA); if the entire intracranial artery was diseased, the most distal, parallel, nontortuous normal segment was measured (third choice). ROI analysis was performed to measure intravascular SI 


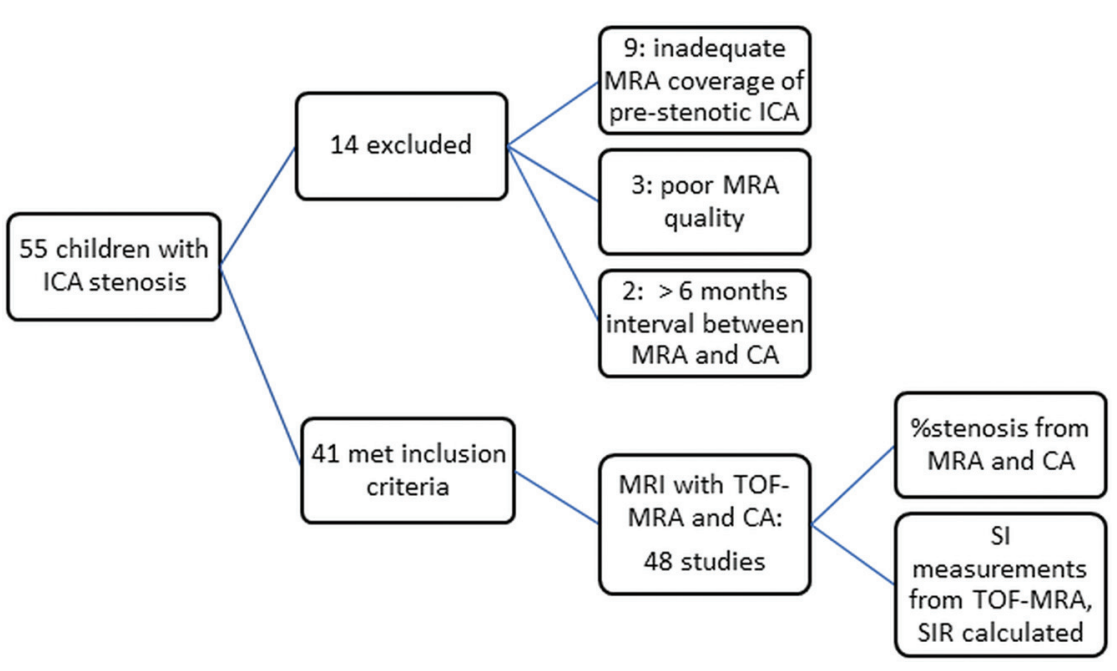

FIG 2. Flow chart showing patient selection for our study. SIR indicates signal intensity ratios.

\section{Statistical Analysis}

Categoric variables were expressed as number and percentage; continuous variables were expressed as median and range. For statistical purposes, stenosis was graded as follows: none $(0 \%)$, mild $(<50 \%)$, moderate $(50 \%-69 \%)$, severe (70\%-99\%), and complete $(100 \%)$, as previously described. ${ }^{24}$ Correlations of percentage stenosis on MRA with percentage stenosis on conventional angiography and with SI ratios were performed using the Pearson correlation; the presence of infarcts and the development of new infarcts were compared with percentage stenosis and SI ratios using a point-biserial correlation. Receiver operating characteristic curve analysis was performed on SI ratios as a determinant

Table 1: Sites of intracranial arterial stenosis in our cohort $\underline{\text { ( } n=70 \text { stenotic segments) }}$

\begin{tabular}{lc}
\multicolumn{1}{c}{ Sites } \\
\hline Right & 14 \\
Left & 12 \\
Bilateral & 22 \\
Associated with infarct & $36 / 70(51.4 \%)$ \\
Specific location & \\
Cervical and petrous & $4(6 \%)$ \\
Cavernous & $3(4 \%)$ \\
Postclinoid & $20(29 \%)$ \\
Postcommunicating and terminal & $21(30 \%)$ \\
Postterminal (Al ACA or Ml MCA) & $22(31 \%)$ \\
\hline
\end{tabular}

Note:-ACA indicates anterior cerebral artery.

Table 2: Underlying diagnosis in our cohort of children with stroke and intracranial arterial stenosis $(n=41)$

\begin{tabular}{lc}
\multicolumn{1}{c}{ Clinical Diagnosis } & No. \\
\hline Moyamoya disease & 15 \\
Neurofibromatosis type 1 with Moyamoya & 6 \\
Trisomy-21 with Moyamoya & 3 \\
Dissection & 2 \\
Primary CNS vasculitis & 3 \\
Varicella vasculitis & 2 \\
TCA & 3 \\
Sickle cell disease with Moyamoya & 3 \\
Other & \\
Systemic large vessel vasculitis & 1 \\
Hemolytic uremic syndrome & 1 \\
Thalassemia with Moyamoya & 1 \\
Hurler syndrome & 1 \\
\hline
\end{tabular}

Note:-TCA indicates transient cerebral arteriopathy.

from TOF-MRA. ROIs were manually drawn on TOF-MRA axial source images (Fig 1). The upper cervical ICA SI was measured at approximately the $\mathrm{C} 2$ vertebral level for the prestenotic segment (henceforth, SI-ICA-pre) and from the MCA for the poststenotic segment (henceforth, SI-ICA-post). Each SI-ICA value was measured as the mean of 2 ROIs drawn on adjacent axial sections or adjacent arterial segments with no overlap of ROIs. Ratios of SI were calculated, as SI-post/SI-pre-stenosis. of percentage stenosis (from CA), from which the area under the curve and threshold value were obtained. Sensitivity, specificity, positive predictive value, and negative predictive value for determining severe ( $\geq 70 \%$ ) stenosis by MRA and SI ratios were calculated, with conventional angiography percentage stenosis as the criterion standard. A $P$ value $<.05$ was considered statistically significant. All analyses were performed with SPSS (Version 25.0; IBM, Armonk, New York).

\section{RESULTS}

Of 55 children with intracranial ICA stenosis, 41 met the inclusion criteria, which resulted in 48 studies with 70 stenotic arteries and 36 associated downstream arterial infarcts. Figure 2 shows the flow chart for patient selection. The median age of our cohort was 11 years (range, 5 months to 17 years). Of these, 19/41 patients $(46.3 \%)$ were girls. MR imaging was performed at $1.5 \mathrm{~T}$ in 25/48 and $3 \mathrm{~T}$ in 23/48 studies. Bilateral stenosis was seen in $20 / 41$ patients $(48.8 \%) ; 11 / 41$ patients $(26.8 \%)$ had stenosis on the right side only and $10 / 41$ patients $(24.4 \%)$ had stenosis on the left side only. The most common site for stenosis (Table 1) was distal to the ICA bifurcation $(22 / 70,31 \%)$, (ie, the MCA), followed by the terminal ICA $(21 / 70,30 \%)$. The most common underlying diagnosis was Moyamoya disease (alone or in association with neurofibromatosis 1 , Trisomy-21, sickle cell disease, or thalassemia) accounting for nearly two-thirds of patients (27/41, 65.9\%). Other diagnoses are shown in Table 2. Associated downstream infarcts were seen in 36/48 studies (75\%), 24/48 (50\%) had nonspecific white matter lesions, and $4 / 48$ (8.3\%) had hemorrhage.

The mean interval between MR imaging and CA was $22.7 \pm$ 32.7 days (range, 0-123 days). Severe stenosis ( $\geq 70 \%$ ) was detected by MRA in 50/70 segments (71.4\%) and by conventional angiography in 46/70 segments (65.7\%) (Table 3). Although there was excellent correlation between MRA and conventional angiographic stenosis (Pearson $R=0.93, P<.001$ ), MRA had a sensitivity, specificity, positive predictive value, and negative predictive value of $42.8 \%, 58.8 \%, 30.0 \%$, and $71.4 \%$, respectively, 
for severe $(>70 \%)$ stenosis. The severity of stenosis on MRA correlated with the infarct burden $\left(\mathrm{r}_{\mathrm{pb}}=0.44, P<.001\right)$. Figure 3 shows 2 relevant sample cases.

Mean ratios of SI (post/pre) were as follows: $1.58 \pm 0.51$ (no stenosis), $1.40 \pm 0.50$ (mild-moderate stenosis, $<70 \%$ ), $0.90 \pm$ 0.48 (severe stenosis, 70\%-99\%), and $0.60 \pm 0.33$ (complete, $100 \%)$, with a significant difference of means by 1-way ANOVA $(P<.001)$. A significant moderate negative correlation was seen between post-/prestenosis SI ratios and percentage stenosis on conventional angiography $(R=-0.54, P<.001)$. Receiver operating characteristic statistics (Fig 4) showed an area under the curve of 0.86 (95\% CI, 0.78-0.94) for using post-/pre-ICA SI ratios to determine severe $(\geq 70 \%)$ stenosis. An SI ratio of 1.00 was determined to be the threshold for obtaining maximum sensitivity and specificity for severe stenosis. By means of this SI ratio cutoff value alone and in combination with MRA percentage stenosis, the sensitivity, specificity, positive predictive value, and negative predictive value for determining severe $(>70 \%)$ stenosis were $97.1 \%, 77.8 \%, 71.7 \%, 97.4 \%$, and $75.5 \%, 100 \%, 100 \%$, and $76.8 \%$, respectively.

Table 3: ICA stenosis severity, comparison of MRA with catheter angiography evaluations ( $n=96$ arteries: 70 stenotic and 26 nonstenotic)

\begin{tabular}{lcc}
\hline$\%$ Stenosis & Arteries on MRA (No.) & Arteries on CA (No.) \\
\hline$\leq 50$ & 31 & 29 \\
$51-69$ & 16 & 21 \\
$70-99$ & 4 & 32 \\
100 & 46 & 14 \\
\hline
\end{tabular}
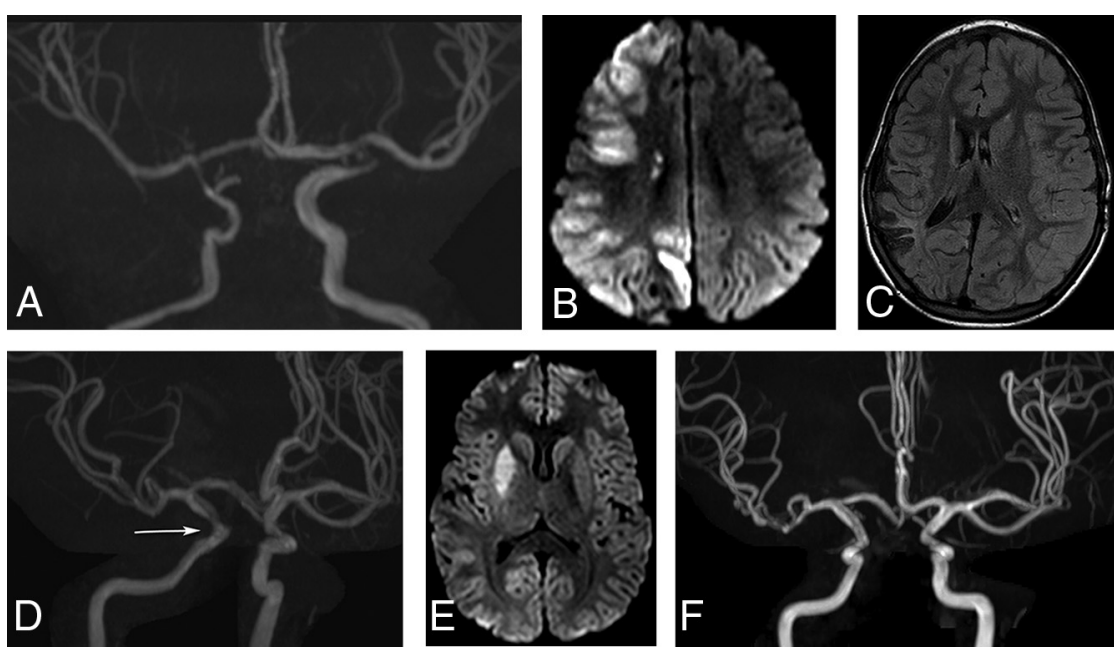

FIG 3. A-C, A 15 -month-old boy with intracranial vasculopathy and bilateral intracranial arterial stenosis. A, Maximum-intensity-projection reformat from TOF-MRA shows bilateral terminal ICA stenosis, measured on MRA as right: $100 \%$; left: $86 \%$. SI ratios were measured as right: 1.0; left: 1.3 . $B$, The child presented with extensive MCA territory infarct. $C, M R$ imaging performed 5 years later. Axial FLAIR image shows no new infarcts in the left cerebral hemisphere. D-F. A 15-year-old boy with right-sided intracranial arteriopathy. $D$, Maximum-intensity-projection reformat from TOF-MRA shows $60 \%$ stenosis of the supraclinoid right ICA, with additional mild narrowing of the proximal $\mathrm{Al}$ anterior cerebral artery and a normal appearance of the left ICA. The SI ratios were measured as right: 0.60 ; left: 1.3. E, The patient presented with acute infarction of the right basal ganglia. F, MRA performed 22 months later shows near-complete resolution of the supraclinoid ICA stenosis, consistent with transient cerebral arteriopathy.

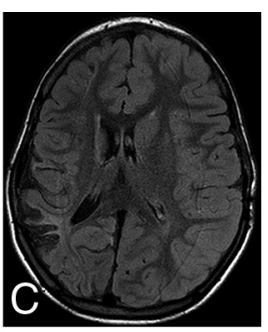

There was a moderate negative correlation between the presence of infarcts and SI ratios $\left(\mathrm{r}_{\mathrm{pb}}=-0.4, P<.001\right)$. The mean post-/pre-SI-ratio for arteries associated with downstream infarcts was $0.81 \pm 0.52$, whereas for arteries without associated infarcts, it was $1.31 \pm 0.55$, the difference being significant by an unpaired $t$ test $(P<.001)$.

\section{DISCUSSION} with time dictate treatment protocols and clinical decisionmaking, including the decision to surgically revascularize. Conventional angiography is the criterion standard for the diagnosis of the presence and severity of intracranial arterial stenosis. ${ }^{19}$ Noninvasive MR angiography and CTA have partially replaced conventional angiography, which has up to a $1 \%$ risk of stroke, a $4 \%$ risk of TIA, and nearly a $1 \%$ mortality rate. ${ }^{25-27}$ Additionally, in children, there are the added concerns with ionizing radiation and general anesthesia. Most institutions worldwide have now accepted MRA as the optimal technique for following pediatric patients with stroke over the course of their disease. However, measuring the severity of mild-moderate stenosis and detecting severe stenosis $(>70 \%)$ by TOF-MRA in children is fraught with challenges resulting from artifacts inherent severity on SI alone would also imply that the physiologic state at the time of scanning would be an important consideration. More recent versions of TOF-MRA have focused on improving the spatial resolution and signal-to-noise ratios using overlapping slices (multiple overlapping thin-slab acquisition) or variable flip angles to maintain the relative spin saturations. How these affect SI in a diseased vessel is not fully known and can result in over- or underestimation of stenosis. To minimize the influence of acquisition parameters, we used the SI ratios instead. Signal intensity ratios on TOF-MRA have the potential to assess the fractional flow reserve of the assessed artery, thus serving as a noninvasive surrogate to identify high-risk intracranial stenosis, its severity, and functional significance. ${ }^{19}$

A recent evaluation of adult patients in the Stroke Outcomes and Neuroimaging of Intracranial Atherosclerosis (SONIA) and Warfarin-Aspirin Symptomatic Intracranial Disease (WASID) trials showed that decreased SI ratios across intracranial arterial stenoses correlated with misery perfusion to the downstream brain territories, thereby 


\section{ROC Curves for Comparisons}

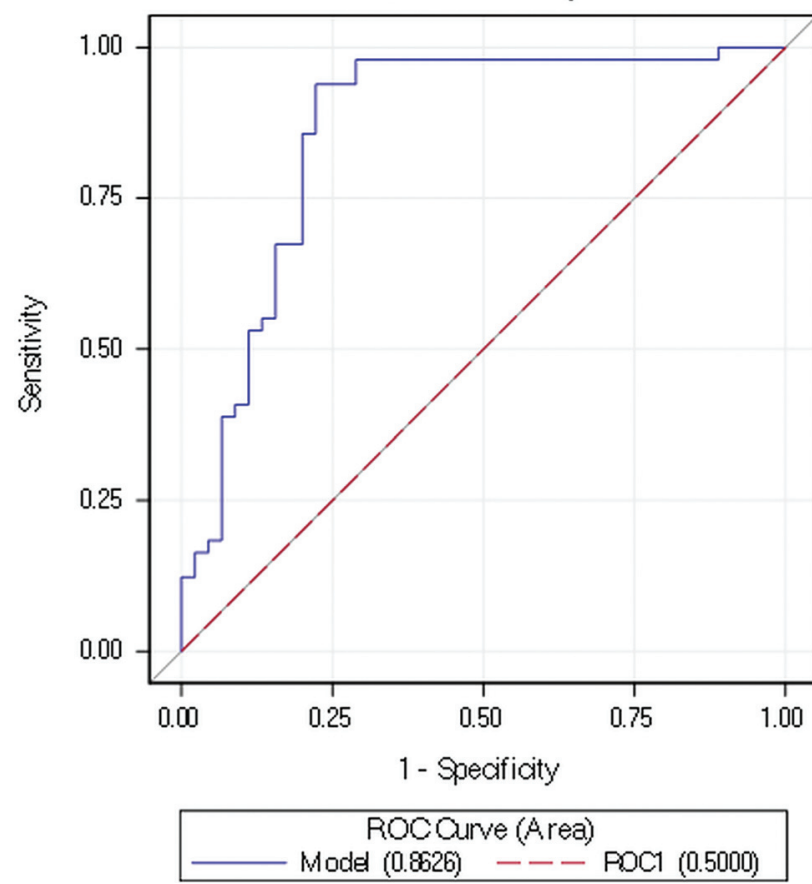

FIG 4. Receiver operator characteristic curve for post-/prestenotic SI ratios to diagnose severe $(>70 \%)$ intracranial arterial stenosis. The area under the curve was 0.86 , with a determined cutoff of 1.00 (see text).

providing a simple and noninvasive predictor of high-risk intracranial stenosis. ${ }^{23,28}$ Signal intensities from TOF-MRA have also been shown to significantly correlate with end-diastolic flow velocities on duplex sonography performed 1 year following pial synangiosis in patients with symptomatic intracranial stenosis. ${ }^{29}$ The reproducibility of SI ratios was shown in a recent study on atherosclerotic intracranial stenosis, with interobserver agreements of $>80 \% .{ }^{30}$ In the present study, we add to this growing body of literature by showing that SI ratios derived from TOFMRA in pediatric patients with stroke correlate with catheter angiographic severity of stenosis, serve as a strong discriminant for diagnosing severe $(>70 \%)$ intracranial stenosis in these children, and are stronger predictors of infarct burden and risk than percentage stenosis.

Although there are studies comparing MRA and conventional angiography in various adult cohorts, ${ }^{31,32}$ this is, to the best of our knowledge, the first time this correlation is being reported in the pediatric stroke literature. The estimation of percentage stenosis for intracranial arteries from TOF-MRA is challenging, with the proximal arterial segments diminishing in size due to reduced flow, poststenotic dilation often being present, TOFMRA artifacts in the stenotic and poststenotic segments, and a normal reduction in size after bifurcation. Selection of the segments used for this analysis is critical. As described above, we used a predefined method, choosing contingency sites if this was not possible. In our cohort of 41 children with 70 stenotic arterial segments, though we found a strong correlation $(R=0.93)$ between MRA and angiographic stenosis, we also showed that MRA was a poor discriminant of severe and mild-moderate intracranial stenosis. Serving as an estimate of the fractional flow across the stenosis, SI ratios had higher sensitivity and specificity than percentage stenosis from MRA (97\% and 78\% versus $43 \%$ and $59 \%$, respectively) and higher positive and negative predictive values ( $72 \%$ and $97 \%$ versus $30 \%$ and $71 \%$, respectively). This finding is not dissimilar to the large body of literature regarding fractional flow reserve assessments in coronary artery disease, which illustrates that percentage stenosis is not an optimal marker for identifying disease of physiologic significance. Due to the invasiveness of intra-arterial wire measurements, noninvasive methods to measure fractional flow reserve have also been developed using coronary CT angiography. ${ }^{33,34}$

While a similar severity of arterial stenosis may have different hemodynamic and functional significance in the cerebral circulation than it does in the coronary tree, it is conceivable that there are better predictors of stroke risk than the severity of stenosis as measured by percentage stenosis. Cerebrovascular reserve studies have shown that the measurement of cerebral blood flow is a strong predictor of stroke risk, independent of the severity of stenosis. ${ }^{35}$ Several different methods have been used for this, including SPECT, PET, CT perfusion, MR imaging perfusion, and blood oxygen level-dependent MR imaging. A retrospective analysis of the WASID trial suggested that impaired collaterals on angiography may be a better predictor of stroke in the territory than percentage stenosis, suggesting a key role for impaired hemodynamics. ${ }^{22-24,28,36-38}$ This finding is not wholly unexpected, given that the intracranial circulation can effectively compensate for a stenotic lesion in a carotid artery by flow across the circle of Willis from the contralateral carotid artery and/or from the posterior circulation. Our finding of a stronger correlation of TOFMRA-derived SI ratios than percentage stenosis with infarct burden implies that SI ratios could serve as a surrogate biomarker for impaired cerebrovascular reserve, independent of the severity of the stenosis. Liebeskind et $\mathrm{al}^{28}{ }^{28}$ in a recent study, had similarly shown that SI ratios derived from TOF-MRA were a strong predictor of increased stroke risk in an adult cohort with intracranial atherosclerotic stenosis.

Our study had some limitations. The retrospective design of the study implied that all data were extracted from medical and imaging records. However, all images were analyzed and postprocessed by study authors using a standard method. Although our cohort included heterogeneous vascular pathologies, these are indicative of the diverse etiologies of pediatric stroke and retain their clinical relevance for neurologists and pediatricians involved in the care of children with stroke. Second, the use of MR imaging scanners of different strengths (1.5 and 3T) could result in some variability in TOF-MRA appearances and the measurement of stenosis. Again, however, the comparison with angiographic stenosis is useful information for clinical settings that commonly toggle between these scanners. Additionally, our use of SI ratios rather than SI itself is expected to negate scanner-related differences. Further research is required to analyze and compare SI ratio differences among scanners. Also, TOF-MRA has several artifacts that are known to affect stenosis measurements and could potentially affect SI values. We attempted to minimize this issue by measuring every value as the mean of 2 ROIs; Liebeskind et $\mathrm{al}^{28}$ using this method, had shown excellent interreader agreement. 
Third, selecting an appropriate segment for placing an ROI for SI was challenging in several cases. Manual placement of the ROI, the level, and location chosen for measurement is subjective. We attempted to maintain consistency by acquiring measurements of arterial SI in the ICA at approximately the C2 vertebral level for the prestenotic segment and from at least 2 arterial segments downstream of the poststenotic segment. Last, intracranial flow measurements are subject to the immediate poststenotic flow effects being altered by the circle Of Willis, as well as by pial/ dural collaterals. ${ }^{39}$ The selection of the MCA as the site for measurement of poststenotic SI was based on this factor: This location would account for compensatory flow from the anterior and/or posterior communicating arteries into the poststenotic artery, for which direct measurements of percentage stenosis would not account.

\section{CONCLUSIONS}

SI ratios measured from TOF-MRA serve as a reliable estimate of the severity of intracranial ICA stenosis in pediatric stroke and can be used as a surrogate for noninvasively following the severity of stenosis across time. These ratios serve as fractional flow measurements, assessing the hemodynamic significance of stenosis and allowing identification of high-risk stenotic lesions. Future prospective studies in pediatric stroke, comparing these with more established cerebrovascular reserve methods, are required to further corroborate our findings.

\section{ACKNOWLEDGMENTS}

We would like to acknowledge the neuroradiologists and neurosurgeons at our institution and the Ontasian Imaging Lab office for their support through this project. We would also like to acknowledge the MR imaging, CT, and interventional radiology technologists who played a key role in the acquisition of images used in this study.

Disclosures: Manohar Shroff-UNRELATED: Expert testimony: Occasional medical expert on birth injury cases; Payment for lectures including service on speakers bureaus: Speakers bureau - one time for BioMarin, stipend for speaking at conference organized by Siemens Brazil - one time.

\section{REFERENCES}

1. Heideman RL, Packer RJ, Albright LA, et al. Tumors of the central nervous system. In: Pizzo PA, ed. Principles and Practice of Pediatric Oncology. 3rd ed. Philadelphia: Lippencott; 1997:633-97

2. National Center for Health Statistics. Deaths, percentage of total deaths, and death rates for the 10 leading causes of death in selected age groups, by race and sex in the United States. 2002. https://www.cdc.gov/nchs/data/nvsr/nvsr53/nvsr53_17.pdf. Accessed June 16, 2019

3. Giroud M, Lemesle M, Madinier G, et al. Stroke in children under 16 years of age: clinical and etiological difference with adults. Acta Neurol Scand 1997;96:401-06 CrossRef Medline

4. Lynch JK, Hirtz DG, DeVeber G, et al. Report of the National Institute of Neurological Disorders and Stroke Workshop on Perinatal and Childhood Stroke. Pediatrics 2002;109:116-23 CrossRef Medline

5. Chung B, Wong V. Pediatric stroke among Hong Kong Chinese subjects. Pediatrics 2004;114:e206-12 CrossRef Medline
6. Fullerton HJ, Wu YW, Zhao S, et al. Risk of stroke in children: ethnic and gender disparities. Neurology 2003;61:189-94 CrossRef Medline

7. Fullerton HJ, Wu YW, Sidney S, et al. Risk of recurrent childhood arterial ischemic stroke in a population-based cohort: the importance of cerebrovascular imaging. Pediatrics 2007;119:495-501 CrossRef Medline

8. Ganesan V, Prengler M, McShane MA, et al. Investigation of risk factors in children with arterial ischemic stroke. Ann Neurol 2003;53:167-73 CrossRef Medline

9. Sträter R, Becker S, von Eckardstein A, et al. Prospective assessment of risk factors for recurrent stroke during childhood: a 5-year follow-up study. Lancet 2002;360:1540-05 CrossRef Medline

10. Chabrier S, Husson B, Lasjaunias P, et al. Stroke in childhood: outcome and recurrence risk by mechanism in 59 patients. $J$ Child Neurol 2000;15:290-94 CrossRef Medline

11. Zimmer JA, Garg BP, Williams LS, et al. Age-related variation in presenting signs of childhood arterial ischemic stroke. Pediatr Neurol 2007;37:171-75 CrossRef Medline

12. Wintermark M, Hills NK, DeVeber GA, et al; VIPS Investigators. Clinical and imaging characteristics of arteriopathy subtypes in children with arterial ischemic stroke: results of the VIPS study. AJNR Am J Neuroradiol 2017;38:2172-79 CrossRef Medline

13. Sébire G, Fullerton H, Riou E, et al. Toward the definition of cerebral arteriopathies of childhood. Curr Opin Pediatr 2004;16:617-22 CrossRef Medline

14. Sébire G, Meyer L, Chabrier S. Varicella as a risk factor for cerebral infarction in childhood: a case-control study. Ann Neurol 1999;45:679-80 CrossRef Medline

15. Earley CJ, Kittner SJ, Feeser BR, et al. Stroke in children and sicklecell disease: Baltimore-Washington Cooperative Young Stroke Study. Neurology 1998;51:169-76 CrossRef Medline

16. Pandey S, Hakky M, Kwak E, et al. Application of basic principles of physics to head and neck MR angiography: troubleshooting for artifacts. Radiographics 2013;33:e113-23 CrossRef Medline

17. Corfield L, Speirs A, McCormack DJ, et al. Time of flight magnetic resonance angiography: a trap for the unwary. EJVES Extra 2010;19:e35-37 CrossRef

18. Takhtani D, Dundamadappa S, Puri AS, et al. Flow artifact in the anterior communicating artery resembling aneurysm on the time of flight MR angiogram. Acta Radiol 2014;55:1253-57 CrossRef Medline

19. Silvennoinen HM, Ikonen S, Soinne L, et al. CT angiographic analysis of carotid artery stenosis: comparison of manual assessment, semiautomatic vessel analysis, and digital subtraction angiography. AJNR Am J Neuroradiol 2007;28:97-103 Medline

20. van den Wijngaard IR, Holswilder G, van Walderveen MA, et al. Treatment and imaging of intracranial atherosclerotic stenosis: current perspectives and future directions. Brain Behav 2016;6: e00536 CrossRef Medline

21. Qureshi AI, Caplan LR. Intracranial atherosclerosis. Lancet 2014;383:984-98 CrossRef Medline

22. Lan L, Leng X, Abrigo J, et al. Diminished signal intensities distal to intracranial arterial stenosis on time-of-flight MR angiography might indicate delayed cerebral perfusion. Cerebrovasc Dis 2016;42:232-39 CrossRef Medline

23. Miura M, Nakajima M, Fujimoto A, et al. Decreased signal intensity ratio on MRA reflects misery perfusion on SPECT in patients with intracranial stenosis. J Neuroimaging 2018;28:206-11 CrossRef Medline

24. Samuels OB, Joseph GJ, Lynn MJ, et al. A standardized method for measuring intracranial arterial stenosis. AJNR Am J Neuroradiol 2000;21:643-46 Medline

25. Hankey GJ, Warlow CP, Molyneux AJ. Complications of cerebral angiography for patients with mild carotid territory ischaemia being considered for carotid endarterectomy. J Neurol Neurosurg Psychiatry 1990;53:542-48 CrossRef Medline 
26. Davies KN, Humphrey PR. Complications of cerebral angiography in patients with symptomatic carotid territory ischaemia screened by carotid ultrasound. J Neurol Neurosurg Psychiatry 1993;56:96772 CrossRef Medline

27. Johnston DC, Chapman KM, Goldstein LB. Low rate of complications of cerebral angiography in routine clinical practice. Neurology 2001;57:2012-14 CrossRef Medline

28. Liebeskind DS, Kosinski AS, Lynn MJ, et al. Noninvasive fractional flow on MRA predicts stroke risk of intracranial stenosis. $J$ Neuroimaging 2015;25:87-91 CrossRef Medline

29. Matsuo S, Nakamizo A, Fujioka Y, et al. Time-of-flight MRA signal intensity predicts the cerebral hemodynamic status after superficial temporal artery to middle cerebral artery anastomosis. J Clin Neurosci 2019;59:124-29 CrossRef Medline

30. Leng X, Ip HL, Soo Y, et al. Interobserver reproducibility of signal intensity ratio on magnetic resonance angiography for hemodynamic impact of intracranial atherosclerosis. J Stroke Cerebrovasc Dis 2013;22:e615-19 CrossRef Medline

31. Verlhac S, Bernaudin F, Tortrat D, et al. Detection of cerebrovascular disease in patients with sickle cell disease using transcranial Doppler sonography: correlation with MRI, MRA and catheter angiography. Pediatr Radiol 1995;25:S14-19

32. Kandeel AY, Zimmerman RA, Ohene-Frempong $\mathrm{K}$, et al. Comparison of magnetic resonance angiography and catheter angiography in sickle cell disease: clinical significance and reliability. Neuroradiology 1996;38:409-16 CrossRef Medline

33. Koo BK, Erglis A, Doh JH, et al. Diagnosis of ischemia-causing coronary stenoses by noninvasive fractional flow reserve computed from coronary computed tomographic angiograms: results from the prospective multicenter DISCOVER-FLOW (Diagnosis of
Ischemia-Causing Stenoses Obtained Via Noninvasive Fractional Flow Reserve) study. J Am Coll Cardiol 2011;58:1989-97 CrossRef Medline

34. Min JK, Koo BK, Erglis A, et al. Usefulness of noninvasive fractional flow reserve computed from coronary computed tomographic angiograms for intermediate stenoses confirmed by quantitative coronary angiography. Am J Cardiol 2012;110:971-76 CrossRef Medline

35. Gupta A, Chazen JL, Hartman M, et al. Cerebrovascular reserve and stroke risk in patients with carotid stenosis or occlusion: a systematic review and meta-analysis. Stroke 2012;43:2884-91 CrossRef Medline

36. Baradaran H, Patel P, Gialdini G, et al. Quantifying intracranial internal carotid artery stenosis on MR angiography. AJNR Am J Neuroradiol 2017;38:986-90 CrossRef Medline

37. Chimowitz MI, Lynn MJ, Howlett-Smith H, et al; Warfarin-Aspirin Symptomatic Intracranial Disease Trial Investigators. Comparison of warfarin and aspirin for symptomatic intracranial arterial stenosis. N Engl J Med 2005;352:1305-16 CrossRef Medline

38. Hirooka R, Ogasawara K, Inoue T, et al. Simple assessment of cerebral hemodynamics using single-slab 3D time-of-flight MR angiography in patients with cervical internal carotid artery stenoocclusive diseases: comparison with quantitative perfusion single-photon emission CT. AJNR Am J Neuroradiol 2009;30:55963 CrossRef Medline

39. Miralles M, Dolz JL, Cotillas J, et al. The role of the circle of Willis in carotid occlusion: assessment with phase contrast MR angiography and transcranial duplex. Eur J Vasc Endovasc Surg 1995;10:42430 CrossRef Medline 